\title{
Use of monoclonal antibody KP1 for identifying normal and neoplastic human mast cells
}

\author{
H-P Horny, G Schaumburg-Lever, S Bolz, M L Geerts, E Kaiserling
}

\begin{abstract}
The monoclonal antibody KP1 (CD68) was used to stain normal and neoplastic monocytes and macrophages in routinely processed, paraffin wax embedded tissue: mast cells also exhibited strong, consistent cytoplasmic immunoreactivity. Light microscopic findings were corroborated by electron microscopical and immunocytochemical findings. The predominant sites of immunoreactivity were the specific intracytoplasmic granules of the mast cells. All mast cell subtypes-that is, normal and reactive mast cells, such as those in lymph nodes exhibiting chronic non-specific lymphadenitis, and malignant or neoplastic mast cells in various types of mastocytosis-reacted with this antibody. This finding is of diagnostic importance, because mast cell proliferation could be mistaken for histiocyte proliferation. It also supports the hypothesis that mast cells derive from the bone marrow.
\end{abstract}

The monoclonal antibody $\mathrm{KP1}$ (CD68) is a reliable reagent for identifying monocytes or macrophages in routinely processed tissue. ${ }^{1-3}$ Micklem et al presented evidence that KP1 recognises the same glycoprotein (molecular mass of about 110000 ) as other widely used antibodies that detect macrophages (Y2/131, EBM11, $\mathrm{Ki}-\mathrm{M} 6$ and $\mathrm{Ki}-\mathrm{M} 7$ ), but can only be used on frozen tissue. ${ }^{4}$ Because of increasing evidence of a close cytogenetic association between human mast cells and the myelomonocytic system, we investigated mast cells in various reactive and neoplastic disorders (including tumours derived from mast cells) for reactivity with KP1 and other antibodies detecting macrophages. We wanted to ascertain if the identification of reagents that consistently stain mast cells, in addition to the well known metachromatic stains (such as Giemsa and toluidine blue) and the naphthol AS-D chloroacetate esterase reaction, ${ }^{5}$ could be of diagnostic value, even if they were not specific for these cells. There was strong and reproducible immunohistochemical staining of normal and reactive and malignant or neoplastic mast cells with the macrophageassociated monoclonal antibody KP1, but none with DAKO-MAC 387. KP1 immunoreactivity has also been noted in a case of systemic mastocytosis by Warnke et al. ${ }^{2}$

\section{Methods}

The tissue investigated, which comprised normal and reactive (hyperplastic) mast cells and malignant or neoplastic mast cells, and the diagnosis in each case are listed in the table. Specimens were fixed in $5 \%$ buffered formalin and embedded in paraffin wax for light microscopical examination. Sections were cut at $5 \mu \mathrm{m}$ and stained with the Giemsa stain and the naphthol AS-D chloroacetate esterase reaction. Immunostaining was performed with the avidin-biotin complex method described by Hsu et al. ${ }^{6}$ The following antibodies against macrophages were used: DAKOMAC 387 and KP1 (CD68), both monoclonal, and antibodies against $\alpha 1$-antitrypsin and $\alpha 1$ antichymotrypsin, both polyclonal (all purchased from Dakopatts, Hamburg, West Germany). The specificity of the immunoreactions was assessed in lymph nodes, where differing numbers of macrophages and histiocytes were stained by these antibodies. Because one of the two monoclonal antimacrophage antibodies, KP1, produced

H-P Horny

$S$ Bolz

E Kaiserling

Department of

Dermatology,

University of

Tübingen, Federal

Republic of Germany

G Schaumburg-Lever

Akademisch

Ziekenhuis,

Rüksuniversiteit,

Gent, Belgium

M L Geerts

Correspondence to:

Professor E Kaiserling,

Pathologisches Institut der

Universität,

Liebermeisterstrasse 8,

D-7400 Tübingen, Federal

Republic of Germany.

Accepted for publication

28 March 1990

Tissue specimens investigated and corresponding diagnoses

\begin{tabular}{lll}
\hline Specimen & Mast cell type & Diagnosis \\
\hline Lymph node & Normal/reactive & Chronic non-specific lymphadenitis \\
Lymph node* & Normal/reactive & Dermatopathic lymphadenitis \\
Tumour & Reactive/hyperplastic & Neurilemmoma \\
Tumour & Reactive/hyperplastic & Epithelioid haemangioma \\
Tumour & Reactive/hyperplastic & (angiolymphoid hyperplasia with eosinophilia) \\
Skin & Neoplastic & Invasive breast carcinoma \\
Skin & Neoplastic & Mrticaria pigmentosa \\
Lymph node, bone marrow & Neoplastic & Systemic mastocytosis \\
Bone marrow & Neoplastic & Systemic mastocytosis \\
Bone marrow & Neoplastic & Systemic mastocytosis \\
Lymph node, bone marrow & Neoplastic & Malignant mastocytosis \\
Lymph node & Neoplastic & Malignant mastocytosis \\
Spleen & Neoplastic & Malignant mastocytosis \\
\hline
\end{tabular}

*Also used for electron microscopic studies.

Mastocytosis was subdivided into systemic mastocytosis (associated with urticaria pigmentosa-like skin lesions and a relatively good prognosis) and malignant mastocytosis (without such skin lesions and generally following a rapidly fatal course). ${ }^{13}$ 


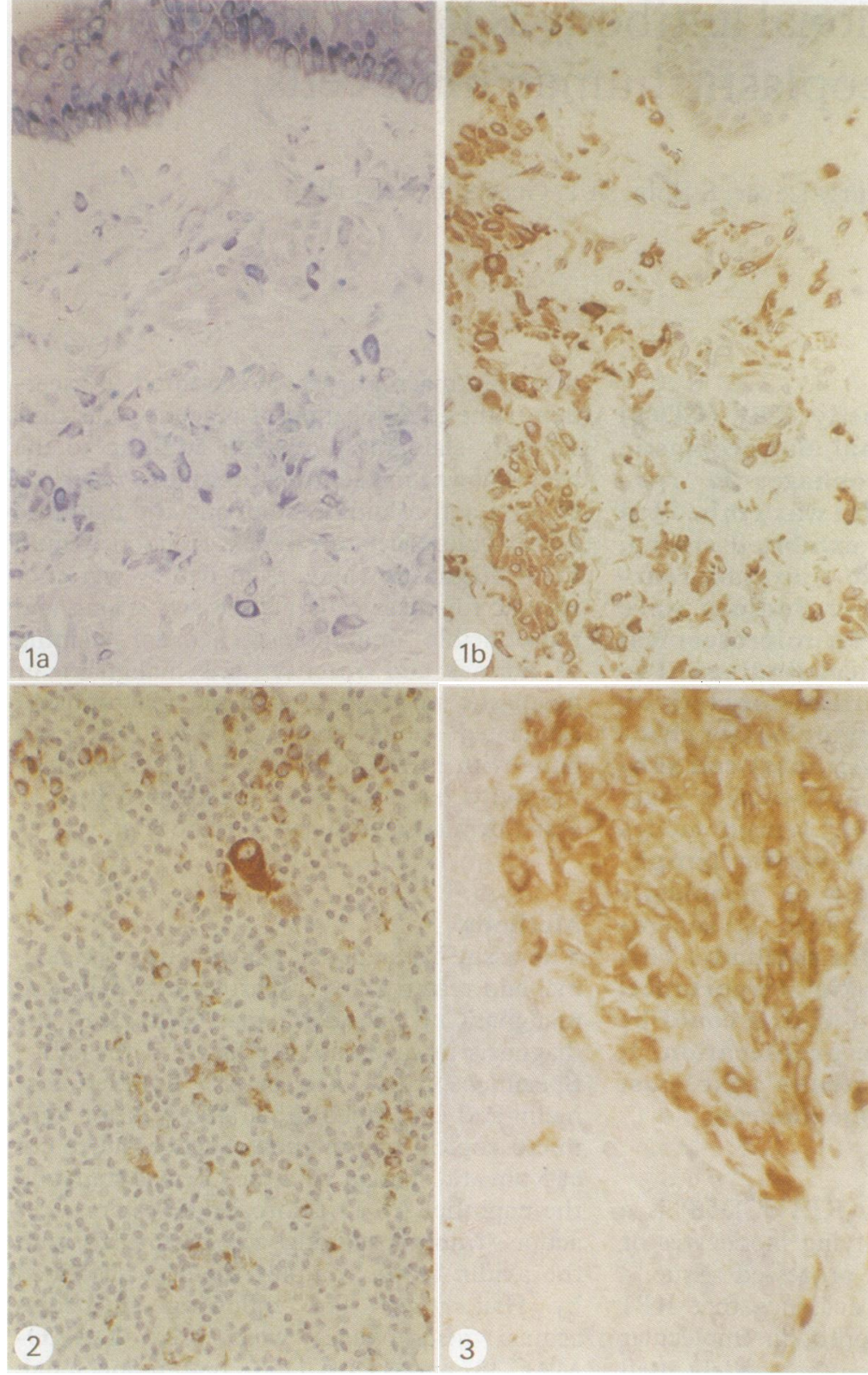

Figure 1 Cutaneous mastocytosis (urticaria pigmentosa). The corium is densely infiltrated by slightly pleomorphic mast cells with metachromatic granules $(A)$. All these cells exhibit intense cytoplasmic immunostaining by the monoclonal antibody $K P 1(B)$. ( $A$ Giemsa; $B$ KP1, ABC method).

Figure 2 Chronic non-specific lymphadenitis in a cervical lymph node. Loosely scattered medium sized macrophages/histiocytes are stained by the monoclonal antibody KP1. The lymphoid cells remain unstained. A fusiform mast cell that exhibits strong, diffuse cytoplasmic reactivity with KP1 is seen (top centre). (KP1, ABC method).

Figure 3 Malignant mastocytosis. This lymph node exhibits patchy infiltration by large, pleomorphic mast cells, all of which are intensely immunostained by KP1 (KP1, $A B C$ method).

strong, consistent cytoplasmic staining in the mast cells of all the specimens examined, further immunocytochemical studies were performed using electron microscopy.

Electron microscopic investigations were carried out on a lymph node draining a congenital cellular naevus. The tissue was fixed in a mixture of $2 \%$ paraformaldehyde and $0.2 \%$ glutaraldehyde in phosphate buffered saline (PBS) (pH 7.4) for four hours. The specimens were then rinsed in PBS, immersed in $0.5 \mathrm{M}$ $\mathrm{NH}_{4} \mathrm{Cl}$ in PBS for one hour, and rinsed again in PBS. ${ }^{7}$ The tissue was dehydrated in graded alcohols and the temperature gradually re- duced to $-35^{\circ} \mathrm{C}$. It was then embedded in Lowicryl at $-35^{\circ} \mathrm{C}$. Thin sections were cut and mounted on nickel grids coated with Formvar.

The immunocytochemical procedure was carried out as follows: After a short wash in PBS (three times for five minutes) the grids were floated on drops of normal goat serum $\left(5^{\circ}\right.$, in PBS) for 10 minutes. They were then transferred to drops of the undiluted primary antibody KP1 (Dako, Hamburg, West Germany) and incubated overnight at $4^{\circ} \mathrm{C}$. The next day they were rinsed in PBS (three times for five minutes) and then incubated in a 1 in 5 solution of goat antimouse IgG G10 (Janssen, Olen, Belgium) Auro Probe immunogold reagent with 1\% Teleostean gelatin (Sigma, Munich, West Germany) in PBS for 60 minutes in the dark. The grids were washed again in PBS (three times for five minutes). The sections were dried, counterstained with $5 \%$ uranyl acetate dissolved twice in distilled water (40 minutes) and lead citrate (10 minutes) and examined with a Zeiss EM10 electron microscope.

\section{Results}

Mast cells were identified in all the tissue specimens by the presence of metachromatic intracytoplasmic granules (shown by the Giemsa stain) and by strong staining for naphthol AS-D chloroacetate esterase. The antibody DAKO-MAC 387 did not stain any of the mast cells, but stained macrophages and immature myeloid cells. Antibodies to $\alpha 1$ antitrypsin and $\alpha 1$-antichymotrypsin each stained a large proportion of the mast cells (irrespective of subtype) in every case. KP1 produced consistent, strong granular cytoplasmic staining of all mast cells in all the tissue specimens (figs 1-3).

In the lymph node exhibiting chronic nonspecific lymphadenitis, in addition to the loosely scattered mast cells, macrophages, sinus histiocytes and plasmacytoid $T$ cells (plasmacytoid monocytes) were stained by $\mathrm{KP} 1$, and, as in mast cells, staining in these cells was intracytoplasmic, diffuse, and granular.

The lymph node examined by electron microscopy exhibited a large number of macrophages containing melanosomes. Macrophage lysosomes were labelled by the antibody KP1. Numerous mast cells were also present: two populations could be distinguished by conventional electron microscopy; one type was characterised by closely packed electron dense granules; the other comprised degranulated mast cells and was characterised by low electron density of the granules, which sometimes seemed to merge to form channels.

Mast cells containing granules exhibited two principal areas of labelling (fig 4): the electron dense granules, with accentuation of labelling in the marginal and most electron dense areas-the gold particles were either disseminated or clustered in groups of three to five; and the extra-granular areas. Labelling by gold particles here could not always be 
related to any particular structures. Small, electron dense granular structures that looked like lysosomes were labelled. No labelling of the rough endoplasmic reticulum, which was plentiful in a few cells, was found. Some cytoplasmic filaments were labelled (fig 4).

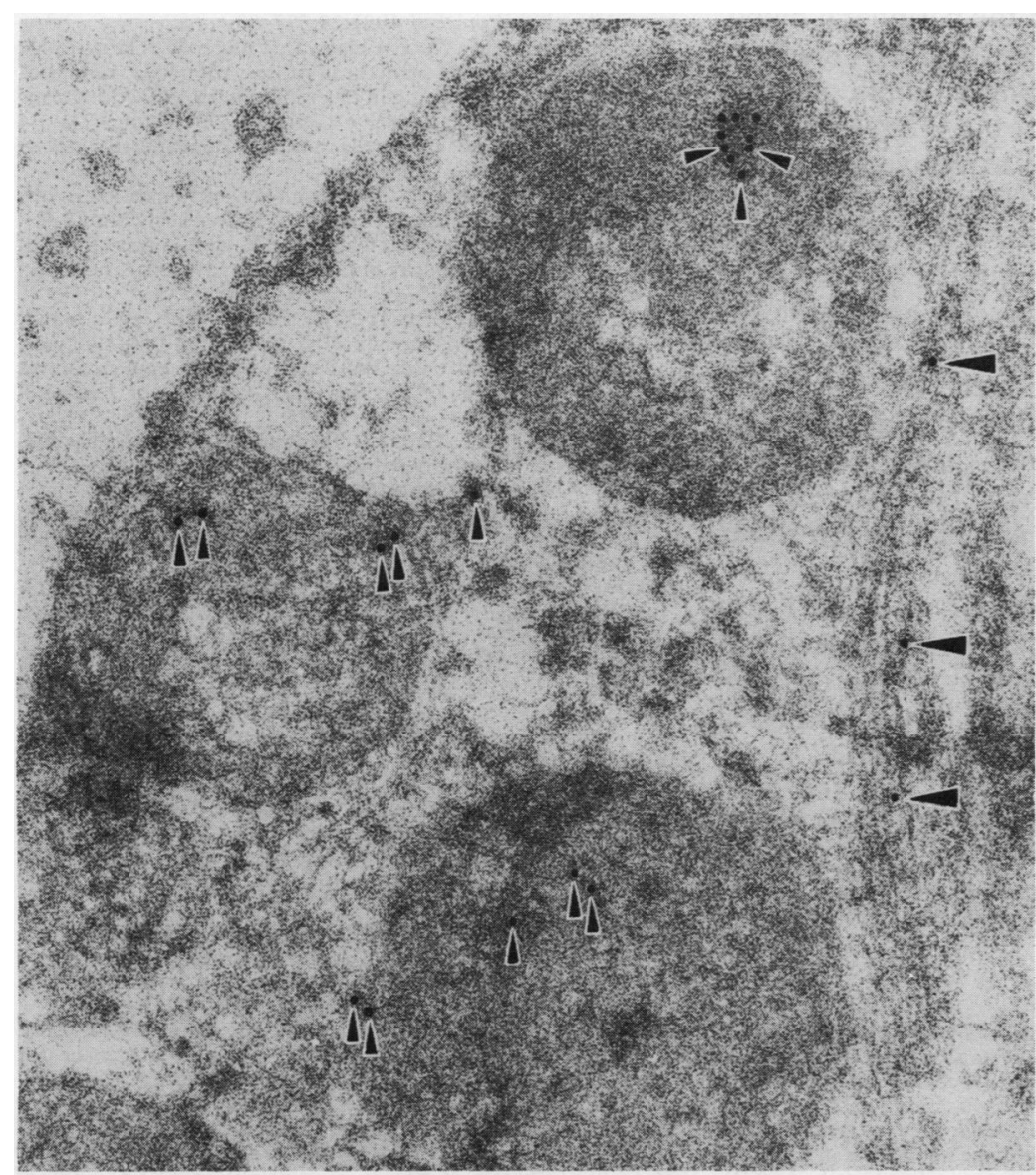

Figure 4 Moderately electron dense mast cell granules with scattered and clustered gold particles (short arrows). A few gold particles in intergranular areas are associated with filamentous structures (long arrows). (KP1).

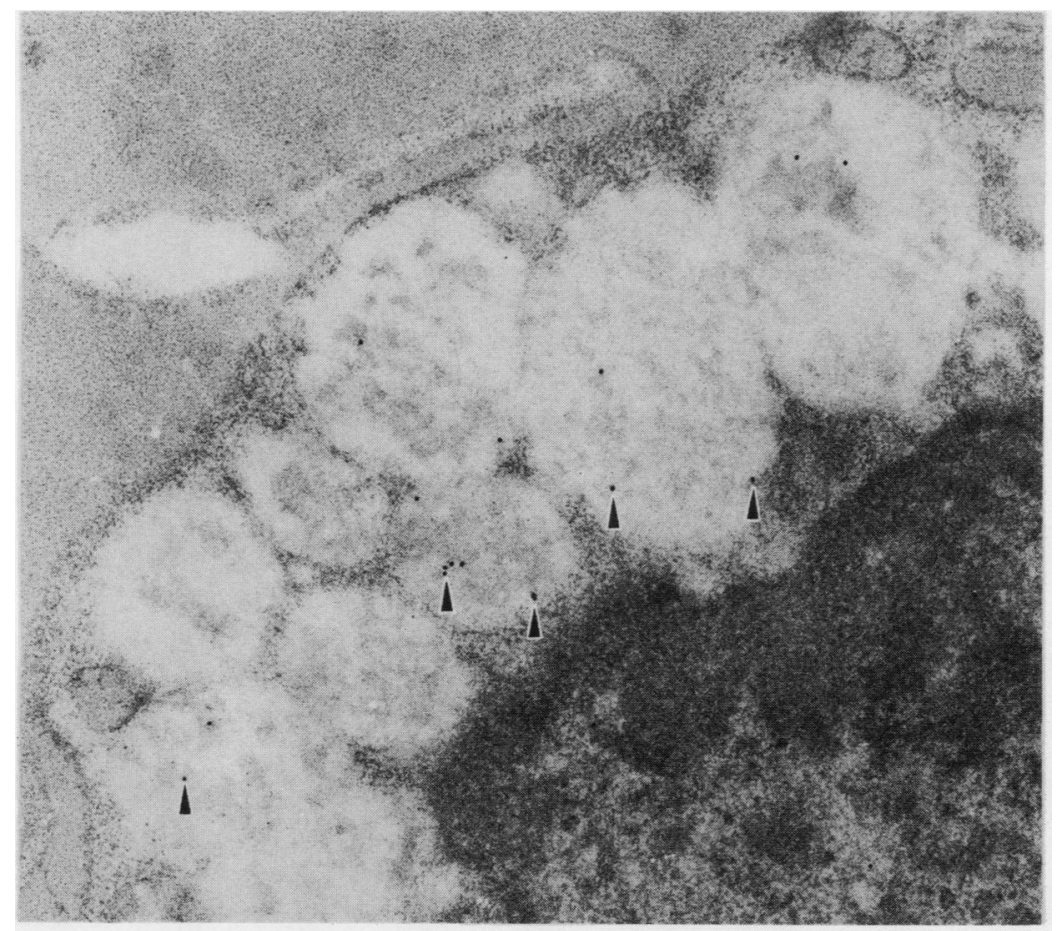

Figure 5 Part of an almost completely degranulated mast cell. Some of the disseminated gold particles are indicated with arrows. (KPI).
Possible labelling of the Golgi apparatus could not be assessed as this structure was not seen in any of the mast cells. No granules with scrolls were seen.

In the degranulated mast cells (fig 5) the channels or granular components, the other more electron dense areas, were extensively labelled. The intergranular cytoplasm was labelled to a lesser extent.

The macrophage phagolysosomes were much more intensely labelled by KP1 than the mast cells and the latter were not labelled at all by the antibody DAKO-MAC 387.

\section{Discussion}

We have shown that there is strong and consistent cytoplasmic staining in normal, reactive, and malignant or neoplastic mast cells by the macrophage-associated monoclonal antibody KP1, first produced and described by Pulford et al. ${ }^{1}$ Electron microscopical and immunocytochemical investigations showed that this reactivity was located predominantly in the specific mast cell granules, even in mast cells that were almost completely degranulated. The reactivity of mast cell granules was considerably weaker, however, than that of the phagolysosomes of macrophages. Our electron microscopic investigations also showed that KP1 immunolabelled reticulum cells, epithelioid cells, pigmented epidermal cells and cells that were probably lymphoid cells, where-as in the macrophages-the lysosomes or phagolysosomes represented the predominant site of immunoreactivity (unpublished observations). So, what are the implications of the finding that mast cells also react with KP1?

Firstly, the reactivity of mast cells with a monoclonal antibody that detects macrophages is interesting as far as the cytogenesis of human mast cells is concerned. Although mast cells are seen only in small numbers in the bone marrow of healthy adults (their presence at this site used to be considered abnormal ${ }^{8}$ ) and are virtually absent from the bone marrow of children, ${ }^{9}$ certain findings indicate a close cytogenetic relation between mast cells and the myelomonocytic system in man:

1 Normal and malignant mast cells and myelomonocytic cells (particularly neutrophils) share enzyme-cytochemical and immunocytochemical properties in that both react for naphthol AS-D chloroacetate esterase ${ }^{5}$ and the leucocyte common antigen, ${ }^{10}$ and both react with the lectin leucoagglutinin ${ }^{11}$ and the monoclonal antibody MY9. ${ }^{12}$

2 There is an extraordinarily high incidence of myelodysplastic and myeloproliferative disorders in patients with systemic mast cell proliferative disorders, particularly the malignant variant. ${ }^{1314}$

3 Chronic myeloid leukaemia may, in rare instances, undergo blastic transformation in which the blast cells exhibit features of atypical mast cells. ${ }^{15-17}$

4 Mast cells exhibit reactivity with the monoclonal antibody KP1 (CD68) and with antibodies against various other surface membrane antigens (CD9 and CD33) associated with a 
late stage of monocyte or macrophage differentiation. $^{18}$

If the hypothesis of a bone marrow origin, not only of rodent but also of human mast cells is accepted, ${ }^{19}{ }^{20}$ the question arises of how these cells pass from the marrow to the connective tissues where they are normally found, as they are never encountered in the peripheral blood. One possible explanation is that marrowderived mast cell progenitors, unlike those of other blood cells, enter the blood stream. These progenitors differentiate in perivascular sites into mature mast cells, which, in contrast to their progenitor cells, can be detected with stains such as Giemsa or toluidine blue. ${ }^{21}$ Of the different types of leucocytes, the heterogeneous population of monocytes or macrophages seems the most likely to include the mast cell progenitors. ${ }^{20}$ This hypothesis is supported by our finding that normal, reactive (hyperplastic), and malignant mast cells react with the macrophage-associated monoclonal antibody KP1.

The reactivity of mast cells with $\mathrm{KP1}$ also presents a more practical problem in that it could lead to mast cell proliferation being taken for histiocyte proliferation if this antibody alone is used to identify macrophages. ${ }^{23}$

We thank Mrs A Mall and Mrs A Adam for their excellent technical assistance, Dr U Engst for help with methodological problems, and Dr M Ruck for help with the manuscript. We also thank Dakopatts (Hamburg) and the Vereinigung der Freunde der Universität Tübingen e.V. for their generous contribution towards the costs of reproduction of the colour micrographs.

1 Pulford KAF, Rigney EM, Micklem KJ, et al. KP1: a new monoclonal antibody that detects a monocyte/macrophage associated antigen in routinely processed tissue sections. $J$ Clin Pathol 1989;42:414-21.

2 Warnke RA, Pulford KAF, Pallesen G, et al. Diagnosis of myelomonocytic and macrophage neoplasms in routinely processed tissue biopsies with monoclonal antibody KP1. Am J Pathol 1989;135:1089-95.

3 Ralfkiaer E, Delsol G, O'Connor NTJ, et al. Malignant lymphomas of true histiocytic origin., A clinical, his- tological, immunophenotypic and genotypic study. $J$ Pathol 1990;160:9-17.

4 Micklem K, Rigney E, Cordell J, et al. A human macrophage-associated antigen (CD68) detected by six different monoclonal antibodies. Br J Haematol 1989;73:6-11.

5 Leder LD. Über die selektive fermentcytochemische Darstellung von neutrophilen myeloischen Zellen und Gewebsmastzellen im Paraffinschnitt. Klin Wochenschr 1964;42:553.

6 Hsu SM, Raine L, Fanger H. Use of avidin-biotin-peroxidase complex (ABC) in immunoperoxidase techniques. $J$ Histochem Cytochem 1981;29:577-80.

7 Roth J, Bendayan M, Carlelalm E, Villiger W, Garavito M Enhancement of structural preservation and immunocytochemical staining in low temperature embedded pancreatic tissue. J Histochem Cytochem 1981;29:663-71.

8 Fadem RS. Tissue mast cells in human bone marrow. Blood 1951;6:614-30.

9 Werner W, Krause AR. Die Gewebsmastzellen im menschlichen Knochenmark. Frankfurt Z Pathol 1965;74:651-8.

10 Horny H-P, Reimann O, Kaiserling E. Immunoreactivity of normal and neoplastic human tissue mast cells. Am J Clin Pathol 1988;89:335-40.

11 Schumacher U, Horny H-P, Welsch U. The lectin leucoagglutinin binds specifically to human granulocytes, monocytes and tissue mast cells: further evidence for common origin of the three cell types. $\mathrm{Br} J$ Haematol 1987;66:405-6.

12 Dalton R, Chan L, Batten E, Eridani S. Mast cell leukaemia: evidence for bone marrow origin of the pathological clone. Br J Haematol 1986;64:397-406.

13 Horny H-P, Parwaresch MR, Lennert K. Bone marrow findings in systemic mastocytosis. Hum Pathol 1985; 16:808-14.

14 Travis WD, Li C-Y, Yam LT, Bergstralh EJ, Swee RG Significance of systemic mast cell disease with associated hematologic disorders. Cancer 1988;62:965-72.

15 Parkin JL, McKenna RW, Brunning RD. Philadelphia chromosome-positive blastic leukemia: Ultrastructura and ultracytochemical evidence of basophil and mast cel differentiation. Br J Haematol 1982;52:663-77.

16 Soler J, O'Brien M, Tavares de Castro J, et al. Blast crisis of chronic granulocytic leukemia with mast cell and basophilic precursors. Am J Clin Pathol 1985;83:254-9.

17 Gabriel LC, Escribano LM, Marie J-P, Zittoun R, Navarro $\mathrm{JL}$. Peroxidase activity in circulating mast cells in blast crisis of chronic granulocytic leukemia. Am J Clin Pathol crisis of chronic

18 Valent P, Ashman LK, Hinterberger W, et al. Mast cel typing: demonstration of a distinct hematopoietic cell type and evidence for immunophenotypic relationship to mononuclear phagocytes. Blood 1989;73:1778-85.

19 Kitamura Y, Yokoyama M, Matsuda H, Ohno T, Mori KJ Spleen colony-forming cell as common precursor for tissue mast cells and granulocytes. Nature 1981;291: $155-60$.

20 Parwaresch MR, Horny H-P, Lennert K. Tissue mast cells in health and disease. Path Res Pract 1985;179:439-61.

21 Galli SJ. Biology of disease. New insights into "The riddle of the mast cells": Microenvironmental regulation of mast cell development and phenotypic heterogeneity. Lab Invest 1990;62:5-33. 